\title{
Brief Analysis of the Spiritual Directions of Yimeng Folk Art - Door Paper-Cuts
}

\author{
Da-yong GU ${ }^{1, a,{ }^{*}}$ \\ ${ }^{1}$ Linyi University, Feixian, Shandong, China \\ alydxmfl@126.com
}

Keywords: Door paper-cuts, Folk art, Spiritual directions.

\begin{abstract}
The door paper-cuts of Yimeng, has lent an aura to the local folk customs, also, such pattern of folk culture has reflected the distinct life style, local customs and cultural perceptions. Therefore, the study of the spiritual directions of door paper-cuts, is more than just explore the cultural perceptions and its origin, or study its local cultural features, we should put much more attention on the cultural connotations and spiritual functions derived from the door paper-cuts.
\end{abstract}

\section{Introduction}

Door paper-cuts, which Chinese people also call it "guajian, guaqian, guomenjian, diaojian, hongjian, menqian, huazhi, etc. represents auspiciousness and luck, is usually used to decorate the doors or windows on traditional Chinese festivals. Therefore, it has got the name "festive paper-cuts". Such door decorations are peculiar to the rural area of china. Shaped like small banner, the door paper-cuts have decorative patterns like human. The tradition of expressing good will through colored paper-cuts can date back to the Han and Jin dynasty [1]. Yimeng door paper-cuts is usually made of red tissue papers or colored papers, rectangular, one foot in length and seven inches in width, and has a patterned boarder, the hollow-out decorations on back has different patterns like square hole cash, the Chinese character "wan", the water ripples, etc. There are small auspicious characters on the top of it, and auspicious words or patterns like "Jiqing Youyu" (which means full of luck and mammon) or "Wugu Fengdeng" (which means bumper grain harvest) in the middle part, and various spiky decorations at the bottom.

\section{The History of Yimeng Door Paper-cuts}

The door paper-cuts is popular in Yimeng region, when it comes to the Spring Festival, colorful door paper-cuts, the spring couplets and door paintings can be seen hanging under the gate lintel of every household, merged with the white snow on the ground, all this will make the days full of festival atmosphere. Inhibited from the art style of ancient colored paper-cuts and stone relief of Han Dynasty, the Yimeng door paper-cuts is usually simple, primitive and rough. These venerable door paper-cuts are now adopted into The Great Treasure of Chinese Fine Arts.

In Yimeng region, the tradition is that five door paper-cuts joined together into one set, and the five door paper-cut should be sorted by colors: first red, then green, thirdly yellow, fourth light red, lastly purple(or blue). Being usually hung under the gate lintel, the door paper-cuts are required to be able to bear determinate pulling force, as a result, the door paper-cuts, its border, and its tassels are tightly linked like net. Apart from this, along with its skillful construction and natural combination, all above help to form door paper-cuts its own characteristics, that is, full of linear rhythm. All door paper-cuts are 
created through chiseling, and the chiseling styles can vary greatly, neither subtle or primitive. In Cangshan and Tancheng county of Linyi, there are chromatic door paper-cuts, which are cut or carved out from five-color papers, firstly we cut the parts out, then put them back together through changing or inlaiding, thus, we will get the colorful decorative effect that consists of both unity and changes.

\section{Yimeng Door Paper-cuts is Conscious Art Form, and Has Strong Spiritual Directions}

Door paper-cuts are created by laboring people freely. Based on direct requirements from life, with the deft skills and cheap papers, folk artists can use what they have locally available, combine the art with utility into paper-cuts of profound implication. Folk artists put their ideas and consciousness into the form of paper-cut, and create inspirations among people; this makes door paper-cuts "conscious art form".

Being component of the great artistic system of paper-cuts, the Yimeng door paper-cuts, usually use the folk culture of country as background, carry auspicious connotations and molded in the form of image. The existence of it, depending on the specific cultural background and living environment, contributes to the unique language with folk features of Yimeng.

\section{The Spiritual Directions Reflected from the Subject and Content of Door Paper-cuts}

The contents of door paper-cuts are mostly auspicious titles, Chinese zodiac, auspicious animals and birds, etc. The patterns and colors are selected according to their homophone, symbolic meaning and connotations, to express the aesthetic sense of people and their desire for a better life. For instance, "the butterflies danced among peonies", butterfly(hú dié) are homophones for "luck"(fú) and longevity(dié) in Chinese, symbolizes auspiciousness and happiness, is used to pray for blessings, besides, butterflies are pretty and dainty, are linked with flowers, so can also symbolizes good relationships or marriage; while peony implies wealth, so, together with butterfly, they represent wealthy, longevity and happy marriage[2]. Being a unique form of Yimeng folk art, the door paper-cuts is deeply influenced by the auspicious culture, and has fulfilled people' life because of its richness in interest, amusement and implication, furthermore has became the spiritual comfort of pursuing luck and avoiding disaster. Embracing the desire for a better future, the folk artists carve or cut with primitive tools, behind it, is the most original spirit of creation and the aesthetics of our long-history nationality [3].

\section{The Spiritual Directions Reflected from the Patterns of Yimeng Door Paper-cuts}

In Yimeng region, it is common that five door paper-cuts joined together into one set, viewed from the pattern, it is mostly a rectangle approximately equals to golden law, and consists of three parts: the central pattern, the surrounding border(except the bottom ) and the tassels. The patterns of door paper-cuts can be divided into two types: the first type, only patterns and without characters, on the central part, the patterns are mostly followers, fruits and vegetables or fish, insects, birds and animals; the second type, the patterns are used to set off the characters, and characters on this type is fifteen at most and one at least. One character, for instance, like "fú"(luck) "shòu"(longevity) and "Xx̌”"(auspice), four characters, like "jí qìng yǒu yú"(full of luck and mammon), "liù hétóng chūn"(everything is flourish), "sì jì píng ān" (pray for safety), guó fù mín qiáng 
(wish our country is wealthy and people are powerful), etc. some of the characters are wroten down vertically in a row, some are divided into two rows. There are also paper-cuts with fifteen words: at the centeral part is a "ji'" (auspice), on the top of it is scroll reads "bā jié píng ān' (healthy and safety), the left and right side are antithetical couplets, "shòu tóng shān yuè yǒng, fú gòng hăi tiān cháng", (happy life and longevity) [4]. No matter how many words there are in the paper-cuts, it expresses the good will of people, and is characteristic of vivid regional nature. Yimeng paper-cuts is simple, fresh, rough and juvenile, entirely different from the elegance of literati art or the rigorous modeling and law of academics.

\section{The Spiritual Directions Reflected from the Color of Yimeng Door Paper-cuts}

The color design of Yimeng door paper-cuts is strongly ornamental, it is fresh, bright, and mix simplicity and complex, it emphasize psychological feelings in theory, while in practice it is controlled by blief, the traditional etiquette and customs. There something in common between Yimeng door paper-cuts and the northern folk art in color characteristics, meanwhile, Yimeng door paper-cuts also has its own features. The five-color paper-cuts is the most popular one. The so called "five-color paper" means a set of door paper-cuts in five colors, which consists of five pieces of door paper-cuts with same form, to attain the beauty united in diversity. The five colors is fundamentally the same as Yimeng folk colored printed cloth, and Yimeng mud toys, and conforms to the habits of local people in appreciation. Red and green, yellow, blue and purple are complementary colors to each other, the layers of five colors is clear, the color saturation is excellent, as a whole, it is bright, the contrasting colors can create distinct visual effect.

There are set forms when post or hang door paper-cuts, first of all, yellow must be placed in the middle, and then the color is sorted in order of pink, red, yellow, green, blue or purple, from left to right. Also, the set forms will be different according to different regions. For instance, in Linyi, Junan county and Cangshan county, the posting order is "red, green, yellow, light red, and purple." however, in Feixian county, Yinan county and Pingyi county, the order is blue (or purple), light red, yellow, red and green. Such set forms has its own reasons: in ancient times, only emperors are allowed to wear yellow robes, so, yellow symbolizes the patriarch of family, should be placed in the middle place; green and red means support, pink and blue are derivatives of red and green, symbolizes fertility and household exuberant. The customs are also vary from places when it comes to choose a single color to post, for instance, some post red when it comes to happy events, and yellow on the kitchen stove; blue or white on the barn and water mill; when it comes to funeral, people post nothing, or just blue or white. Actually, the door paper-cuts is not only artistic means to express mind and emotions, but also the company of etiquette in life, the indispensible spiritual comfort of life.

\section{The Spiritual Directions Reflected from the Stylized Modeling of Yimeng Door Paper-cuts}

The folk features of Yimeng door paper-cuts makes its subjects, the implication and the forms stylized, which also has propelled folk artists to increase their summarizing ability, to make choices on the creative process. Therefore, the door paper-cuts are vivid, exaggerated, and symbolic and allows for more imagination. Never have these folk artists treated their crafts as art, to think or explore, they staring at the real world, and turn the images in their mind into creations, this embodies their perceptual thinking concretely [5]. 


\section{The Advance of Spirits in Yimeng Door Paper-cuts}

The Yimeng door paper-cuts embody the traditional Chinese thought of Yinyang and Wuxing. Influenced by the thought of Yinyang, the number of the door paper-cuts is usually singular, on mall gates the number is five, on bigger one it's seven, singular equals to Yang, plural equals to Yin. Singular symbolizes masculine traits and prosperity, besides,being the main colors, green and red are called "joyous color" by people, people think that the two colors symbolizes the combination of Yin and Yang, the laws of union between vitalities. Five color is the general name of green, yellow, red, white and black, is corresponding to the Wuxing. The posting order of Yinyang door paper-cuts is red at the eastern, green at the western, and yellow at the center. Yellow symbolizes nobility, reflects the rank etiquette and customs. Such kind of color schemes has taken the color contrast into consideration, but also reflects the influence from traditional thought of Wuxing.

\section{Summary}

The strong rustic flavor and folk features are the vital force of Yimeng door paper-cuts during the times when science and technology are developing rapidly. To review Yimeng door paper-cuts in the view of modern art, to learn the "form" is more recreation of traditions, rather than simple copy. To learn the "imagery", is to study the desire for better future of people, so the auspicious meaning behind traditions applies to modern design philosophy as well. The rough, rustic, and wild features, the true, colorful, extensive and positive contents, along with the artistic style of expressing emotions through image, all above reflect the human feature of aesthetic thoughts of Confucianism and Taoism, the human feature of traditional Chinese culture just embodies the very cultural thought.

\section{References}

[1] Li Xiaoyan, The Folk Paper Cutting--Door Paper-cuts and Window Paper-cuts[J]. Art and Literature for the Masses, 2011(3): 189.

[2] Wang Haixia, Chinese Folk Fine Art Sociology[M].Nanjing, Jiangsu Fine Arts Publishing House, 1995:28.

[3] Ge Chunxue, The Value and Characteristics of Folk Paper Cutting [J]. Chenjing, The Study of Chinese Paper Cutting [M]. Beijing, Beijing Fine Arts Publishing House, $1992,114$.

[4] Wang Haixia, Chinese Folk Fine Art Sociology [M].Nanjing, Jiangsu Fine Arts Publishing House, 1995:70.

[5] Chenjing, The Study of Chinese Paper Cutting [M]. Beijing, Beijing Fine Arts Publishing House, 1992, 18. 